\title{
Perfil epidemiológico de crianças envolvidas em bullying
}

\author{
Epidemiologic profile of children involved in bullying
}

\author{
Camila Girardi Fachin¹, Carmen Silvia Molleis Galego Miziara²
}

Fachin CG, Miziara CSMG. Perfil epidemiológico de crianças envolvidas em bullying. Saúde, Ética \& Justiça. 2012;17(1):30-7.

RESUMO: O bullying é caracterizado por ações negativas (agressões físicas, verbais ou psicológicas) sofridas por um estudante, repetidamente ao longo do tempo, que têm como agente um ou mais estudantes, devendo haver um desbalanço de forças entre o agressor e a vítima. São inúmeras as consequências desta prática, tanto para a vítima como para o agressor, como dificuldade de aprendizado, mau aproveitamento escolar, diminuição da autoestima, ideações suicidas e, até, tentativas de suicídio. Tem-se observado um aumento na incidência do fenômeno bullying, em diversos países nas últimas décadas, inclusive em nosso país. O objetivo deste estudo é mapear a incidência do bullying relatada na literatura e traçar um perfil epidemiológico, tanto do agressor quanto da vítima. A prevalência encontrada de bullying nos diversos países e no Brasil atinge níveis alarmantes. Nos últimos 10 anos, a prevalência de bullying nos Estados Unidos tem se mantido relativamente estável, ao redor de $40 \%$. Prevalência semelhante é observada em países europeus e latino-americanos, como a Colômbia. No Brasil, a prevalência de bullying encontrada é um pouco abaixo da vista na literatura, porém observa-se aumento da prevalência entre 2005 e 2011, com uma tendência em se atingir os patamares observados na literatura estrangeira. Em relação ao sexo do agressor, a maioria dos estudos demonstra que os meninos estão mais envolvidos com o bullying físico e as meninas, com o bullying verbal ou indireto. Quanto às características psicológicas, a típica vítima é aquela com pouca habilidade de socialização, tímida, reservada e com baixa autoestima. O agressor tem em sua personalidade traços de desrespeito e agressividade, e possui uma tendência a atos delituosos na vida adulta. As consequências do bullying têm um potencial devastador na vida jovem e adulta destes indivíduos. Tanto vítimas quanto agressores precisam ser identificados e amparados com políticas específicas e eficazes.

DESCRITORES: Bullying/psicologia; Criança; Perfil de saúde; Psicologia da criança/educação; Comportamento infantil/psicologia.

1. Pós-graduanda lato sensu do curso de Especialização em Medicina Legal e Perícias Médicas da Faculdade de Medicina da Universidade de São Paulo.

2. Professora do curso de Especialização em Medicina Legal e Perícias Médicas da Faculdade de Medicina da Universidade de São Paulo.

Endereço para correspondência: Camila Girardi Fachin. Av Prof Noé Azevedo, 208 cj 112. Vila Mariana. São Paulo, SP. CEP 04017-000. E-mail: camilafachim @ onda.com.br 


\section{INTRODUÇÃO}

$B$ sllying é definido por Dan Olweus, um pioneiro no estudo desta entidade, da seguinte maneira: "Um estudante sofre bullying ou é vitimizado quando é exposto, repetidamente ao longo do tempo, a ações negativas por parte de um ou mais estudantes ${ }^{1}$." Essas ações negativas são caracterizadas por: tentativa ou real e intencional injúria ou desconforto causados por outra pessoa. Elas consistem em contato físico, palavras, gestos ou feições obscenas, ou, ainda, exclusão intencional de um grupo ${ }^{[2]}$. Para que seja caracterizado o bullying, deve existir um desbalanço de forças entre aquele que intimida e o que é intimidado. Para estudantes de força física ou mental similares, não se aplica esse termo ${ }^{2,3}$.

Há, ainda, uma definição legal de bullying na legislação do estado de Massachusetts, EUA: "O uso repetido, por um ou mais alunos, de expressões verbais, escritas ou em meio eletrônico, ou ato físico, ou gesto, ou a combinação de quaisquer deles, dirigida a uma vítima, que: (a) cause dano físico ou emocional a vítima ou dano a sua propriedade; (b) faça com que a vítima sinta um medo razoável de dano a si ou a sua propriedade; (c) crie um ambiente hostil na escola para a vítima; (d) infrinja os direitos da vítima na escola; (e) materialmente e substancialmente prejudique o processo de educar ou a ordem na escola ${ }^{4}$.

O termo bullying é de origem inglesa, entretanto sua adoção universal decorre da dificuldade de tradução em outras línguas, devido a seu amplo conceito. Sendo assim, ficou acertada a adoção da palavra inglesa por diversos países, na Conferência Internacional Online School Bullying and Violence, em 20055

Os personagens deste fenômeno podem ser divididos em vítimas, agressores e espectadores. Há ainda uma quarta categoria, aquela na qual o indivíduo, dependendo da circunstância, age como agressor ou vítima. $\mathrm{O}$ agressor pode ser um único indivíduo ou um grupo, o que pode também ser estendido às vítimas, únicas ou um grupo. No contexto escolar, na maioria das vezes, trata-se de um único indivíduo (o agressor) que maltrata, ameaça e agride um outro indivíduo (a vítima) ${ }^{1}$.

Então, para que o bullying ocorra, três critérios devem ser preenchidos: (1) comportamento agressivo com intenção de prejudicar; (2) realizado repetidamente por um período de tempo; (3) relação interpessoal caracterizada por desigualdade de poder $^{1}$. E tudo isso ocorre sem que haja aparente provocação da vítima.

Pode-se classificar o bullying como direto ou indireto ${ }^{1,2,6}$. No primeiro, ocorre um ataque direto à vítima, que pode ser físico ou verbal. Já o indireto é caracterizado por isolamento social, como ocorre na disseminação de rumores, e exclusão intencional de um grupo ${ }^{1,2}$.

$\mathrm{Na}$ atualidade, em decorrência dos avanços tecnológicos, tem-se ainda uma nova forma de bullying: o cyberbullying. Ele consiste no uso de meios eletrônicos como ligações, mensagens de texto, email, postagens nos sites de relacionamento etc., para sobrepujar alguém ${ }^{4}$. Esta nova modalidade é bastante preocupante devido ao imensurável efeito multiplicador do sofrimento das vítimas ${ }^{6}$, já que o alcance destes ataques extrapola em muito os muros da escola. São inúmeras as potencializações do cyberbullying em relação ao bullying tradicional ${ }^{4}$ : comentários ou mensagens podem ser construídos de forma mais elaborada (e cruel), e não momentânea como no bullying tradicional; pode-se ficar no anonimato ou utilizar-se de pseudônimos; o agressor não precisa encarar sua vítima; a intervenção dos espectadores no cyber espaço fica bastante restrita em relação à vida real, bem como a intervenção e repressão por parte de pais e professores 4 .

Há inúmeros trabalhos na literatura científica que enumeram as consequências desta prática, tanto para a vítima como para o agressor ${ }^{5,7-9}$ e, inclusive, também para os espectadores ${ }^{6}$. Essas consequências podem ser de caráter mais precoce, como a dificuldade de aprendizado, o mau aproveitamento escolar, a diminuição da autoestima, ou, ainda mais graves, as ideações suicidas e até as tentativas de suicídio ${ }^{2,4,10-12}$. Como consequências tardias, os agressores e agredidos tendem a ter comportamento violento e há risco aumentado do envolvimento do agressor, na adolescência e início da vida adulta, em crimes $^{4,13}$.

Tem-se observado um aumento na incidência do fenômeno bullying em diversos países nas últimas décadas ${ }^{2,14,15}$. E, além disso, episódios de verdadeiro horror nas escolas têm sido amplamente divulgados por noticiários de todo o mundo, nos quais jovens alunos assassinam friamente seus pares ${ }^{[6]}$. Na maioria destes episódios, o aluno autor dos disparos se sentia previamente perseguido, ameaçado e atacado por seus colegas, como mostra um relatório elaborado pelo Serviço Secreto americano com estudantes envolvidos em 37 episódios de tiroteio nas escolas, nos Estados Unidos ${ }^{16}$. Em outro estudo, que analisou 220 mortes associadas à violência nas escolas, provou-se que em 172 assassinatos cometidos por estudantes entre 1994 e 1999, o estudante agressor tinha 2,6 vezes mais chance de ter sido vítima de bullying 
que o estudante que ele assassinara ${ }^{17}$.

No Brasil, a realidade não é diferente do restante do mundo. Há algumas publicações que mostram também o aumento da prevalência de bullying $5,10,18,19$.

Somado a esse aumento alarmante, têm-se as consequências devastadoras nas vidas destes jovens, relatadas acima, resultando na importância do presente estudo no contexto atual.

O objetivo deste estudo é mapear a incidência do bullying relatada na literatura, nos diferentes países e também no Brasil. E, ainda, coletar dados para traçar um perfil epidemiológico tanto do agressor como também do agredido, no que se refere à idade mais prevalente de acometimento, sexo e características da personalidade. E, por fim, observar se há diferença neste perfil epidemiológico entre as crianças brasileiras e as de outras partes do mundo.

\section{MÉTODO}

Foi realizado levantamento bibliográfico utilizando os descritores (constantes do DeCS) "bullying" e "crianças" nas bases de dados PubMed (http://www.ncbi.nlm.nih.gov/pubmed) e Lilacs (http://lilacs.bvsalud.org) entre os anos de 2000 e 2011. Dos artigos encontrados, foram selecionados aqueles cujo objetivo foi estudar a prevalência de bullying em determinada localidade. Foram incluídos artigos estrangeiros e brasileiros.

\section{RESULTADOS}

$\mathrm{Na}$ pesquisa realizada foram identificados nove artigos estrangeiros e quatro nacionais nos quais havia sido estudada a prevalência de bullying em determinada população de crianças. Nas Tabelas 1 e 2 os mesmos foram sumarizados.

Em estudo conduzido pelo National Institute of Child Health and Human Development, em 2001, nos Estados Unidos, com uma amostra de 15.686 alunos da $6^{\text {a }}$ a $10^{\text {a }}$ série, $29,4 \%$ dos alunos reportaram envolvimento em bullying moderado ou frequente, como agressores; e 16,9\% como vítimas $^{20}$. O sexo masculino foi prevalente, tanto entre agressores quanto entre vítimas. Houve uma diminuição gradual do envolvimento com bullying da $6^{\underline{a}}$ para a $10^{\mathrm{a}}$ série.

No mesmo ano, Wolke et al. ${ }^{21}$, ao estudarem alunos ingleses e alemães, encontraram uma maior prevalência de bullying quando comparada com a casuística americana, entretanto a faixa etária deste estudo foi menor, 6 a 8 anos, contra 12 a 15 anos no estudo de Nansel et al. A prevalência de vítimas, aos 6 anos, foi de 54,7\% na Inglaterra e $39 \%$ na Alemanha, enquanto que a de agressores foi de $14 \%$ e $21,9 \%$, respectivamente. Esses autores também reportaram a prevalência do sexo masculino como agressores.

Revisando casuísticas de bullying de $1^{\text {a }}$ a 5 a séries, de diversos países (Noruega, Suécia, Dinamarca, Finlândia, Alemanha, Espanha, Itália, Inglaterra, Escócia, Irlanda, Austrália, Japão, Canadá e EUA), em 2003, Dake et al. ${ }^{2}$ relataram prevalências muito díspares nos diversos países, desde $11,3 \%$ na Finlândia até 49,8\% na Irlanda. Observaram também que com o passar dos anos a incidência de bullying cai e que meninos estão mais frequentemente envolvidos em bullying físico que meninas; entretanto, em se tratando de bullying verbal, a prevalência é a mesma entre os sexos.

Em estudo com 2766 alunos holandeses de 9 a 12 anos, em 2004 houve prevalência de 16,2\% de vítimas e 5,5\% de agressores, quando considerados atos com frequência de algumas vezes no mês até todos os dias ${ }^{8}$. Entretanto, 44,6\% relataram ter sido vítima pelo menos uma vez, e $37,5 \%$ referiram ter sido agressores por pelo menos uma vez. No grupo de agressores, os meninos foram mais prevalentes; já no grupo vítimas, não houve diferença entre os sexos.

Em 2008, na Colômbia, Cepeda-Cuervo et al. ${ }^{15}$ estudaram 3226 alunos, da $6^{\underline{a}}$ a $11^{\underline{a}}$ série, com idades entre 10 e 20 anos, e constataram que $20,8 \%$ já sofreram algum grau de bullying; que $21,8 \%$ sofrem com muita frequência e que ocorre diminuição dessas prevalências com o passar das séries. Neste mesmo ano, também na Colômbia, outros autores estudaram a prevalência em 2542 alunos, da $6^{\mathrm{a}}$ a $8^{\mathrm{a}}$ série, com idade média de 12 a 13 anos e constataram que $51,4 \%$ dos estudantes já foram vítimas, $24,3 \%$ com frequência, e que $43,6 \%$ já atuaram como agressores, 24,7\% com frequência ${ }^{22}$. As formas de agressão mais frequentemente observadas foram ridicularização e agressão física; em 83\% dos casos a ação ocorria na presença de outras pessoas (testemunhas ou espectadores).

Due e Holstein ${ }^{23}$, em 2008, compilaram os dados de dois grandes estudos internacionais da Organização Mundial da Saúde (OMS): o Health Behaviour in School-aged Children (HBSC) e - Global School-based Student Health Survey (GSHS). Esses dois estudos avaliaram a prevalência de bullying em 66 países, em crianças de 13 a 15 anos. O primeiro, HBSC, avaliou a porcentagem de crianças que foram vítimas de bullying pelo menos uma vez nos últimos dois meses, em países da Europa, da América do Norte e em Israel, de 2001 
a 2002. E o segundo, o GSHS, a porcentagem de vítimas de bullying pelo menos uma vez nos últimos 30 dias, em 31 países de diversos continentes. Totalizaram 218.104 crianças, com os seguintes resultados: $32,1 \%$ sofreram bullying pelo menos uma vez nos últimos dois meses (HBSC) e $37,4 \%$ sofreram bullying por pelo menos um dia nos últimos 30 dias (GSHS). Os países com índices mais altos de vítimas foram Egito (60,6\%), Lituânia (63,6\%) e Zâmbia $(64,8 \%)$. No total geral, houve uma tendência a maior prevalência no sexo masculino $(36,9 \%)$ em relação ao feminino $(32,3 \%)$.

Outro estudo conduzido por Glew et al. ${ }^{9}$, também em 2008, com 5.391 alunos das $7^{\mathrm{a}}$, $9^{\underline{a}} \mathrm{e}$ 11aㅡ séries, na costa oeste dos Estados Unidos, evidenciou $15 \%$ de alunos vítimas de bullying, $7 \%$ de agressores e $4 \%$ que agiam tanto como agressores quanto como vítimas. Observou-se que tanto vítimas como agressores tinham duas vezes mais chance de se sentirem inseguros na escola e tristes na maioria dos dias. Avaliando 346 alunos do ensino fundamental de escolas da Flórida, Estados Unidos, Pergolizzi et al. encontraram que $82,7 \%$ deles vêem o bullying como um problema, sendo que $89 \%$ já testemunharam. Do total de alunos, $49,1 \%$ declararam já ter sido vítima de bullying e $43,6 \%$ admitiram já ter agredido. Nos agressores, não houve diferença estatisticamente significativa quanto ao sexo, porém os padrões de bullying são diferentes. O menino está mais ligado a agressões físicas e ameaças; já, as meninas, a fofocas e à exclusão. Com relação ao cyberbullying, $31,1 \%$ dos entrevistados foram afetados diretamente por ele.

Em se tratando de publicações com casuísticas nacionais, tem-se um estudo realizado pela Associação Brasileira Multiprofissional de Proteção à Infância e Adolescência (ABRAPIA), em 2002, com 5.500 alunos de $5^{\text {a }}$ a $8^{\text {a }}$ séries, do Rio de Janeiro-RJ5. Neste estudo, tem-se que $40,5 \%$ dos alunos admitiram estar envolvidos com bullying, $16,9 \%$ como vítimas, $12,7 \%$ como agressores e $10,9 \%$ ora como vítimas, ora como agressores. Das vítimas, apenas $41,6 \%$ reportaram o fato a suas famílias ou professores. Desses que solicitaram ajuda, somente $23,7 \%$ tiveram êxito em conseguila. Entre os agressores, 51,8\% relataram terem ficado impunes em relação aos seus atos, não tendo recebido nenhuma repreensão ou advertência.

Francisco e Libório $^{19}$, em 2009, compararam 283 alunos da $5^{\text {a }}$ e $8^{\underline{a}}$ séries, de duas escolas de Presidente Prudente, SP, uma central e outra na periferia. Constataram uma prevalência na $5^{\underline{a}}$ série de $12,8 \%$ de vítimas na escola central versus $17 \%$ na periférica. Já na $8^{a}$ série essa prevalência foi de $15,4 \%$ e $14,9 \%$, respectivamente. Tem-se, portanto, que as prevalências nestas duas séries não foram estatisticamente diferentes. Entretanto, ao analisar-se o tipo de bullying, há diferença. $\mathrm{Na}$ $5^{\text {a }}$ série prevaleceram as agressões físicas, já, na $8^{a}$ série, as provocações. O sexo masculino foi mais prevalente como agressor, mesmo quando a vítima era menina.

Em 2010, Malta et al. ${ }^{18}$ publicaram os resultados da Pesquisa Nacional de Saúde do Escolar (PeNSE), realizada em 2009, em parceria entre o Instituto Brasileiro de Geografia e Estatística (IBGE) e o Ministério da Saúde, em 26 capitais brasileiras e no Distrito Federal, com 60.973 alunos da $8^{a}$ série de escolas públicas e privadas. Desses alunos, 5,4\% reportaram serem vítimas de bullying quase sempre ou sempre nos últimos 30 dias, $25,4 \%$ reportaram ser raramente ou algumas vezes, no mesmo período. A capital com maior prevalência de vítimas foi Belo Horizonte, MG, $(6,9 \%)$ e a de menor foi Palmas, TO, (3,5\%). O sexo masculino teve maior prevalência como vítima $(6,0 \%$ versus $4,8 \%$ no sexo feminino). Não houve diferença entre escolas públicas $(5,5 \%)$ e privadas $(5,2 \%)$, exceto em Aracaju, SE, onde houve maior prevalência nas escolas privadas.

Ao avaliar 1.075 alunos de $1^{\underline{a}}$ a $8^{\mathrm{a}}$ séries em Pelotas, RS, em 2011, Moura et al. ${ }^{10}$ reportam uma prevalência de vítimas de bullying de $17,6 \%$, sendo a forma mais comum a verbal. Entre as vítimas, referem que $47,1 \%$ das mesmas foram também agressores, que predomina o sexo masculino e que há importante associação com hiperatividade e problemas de relacionamento entre os colegas.

\section{DISCUSSÃO}

A maioria dos estudos aqui apresentados faz a coleta de dados através de questionários preenchidos pelas próprias crianças, acarretando um viés do ponto de vista epidemiológico, pois a resposta está intrinsecamente ligada a aspectos comportamentais. As definições de bullying utilizadas são muito próximas, fazendo com que seus resultados sejam realmente comparáveis. O que dificultou em algum grau a comparação entre os estudos foi a frequência dos episódios de bullying considerada em cada um deles. A própria definição de bullying, apresentada na introdução deste artigo, não define claramente qual seria essa frequência, apenas refere "repetidamente ao longo do tempo", sendo assim, cada autor determina em seu estudo as faixas de tempo consideradas, por exemplo, uma ou duas vezes no semestre, algumas vezes ou toda semana ${ }^{20}$, ou, ainda, diariamente, uma vez na semana, uma vez ao mês, várias vezes por mês, uma vez ao ano ${ }^{22}$. 
Fachin CG, Miziara CSMG. Perfil epidemiológico de crianças envolvidas em bullying.

Tabela 1. Estudos estrangeiros de prevalência de bullying

\begin{tabular}{|c|c|c|c|c|}
\hline ANO & AUTORES & LOCAL E PERÍODO & POPULAÇÃO & PREVALÊNCIA GERAL \\
\hline 2001 & Nansel TR, et al..$^{20}$ & $\begin{array}{l}\text { Estados Unidos, } \\
\text { Primavera de } 1998\end{array}$ & $\begin{array}{l}15.686 \text { alunos da } 6^{\mathrm{a}} \text { a } 10^{\mathrm{a}} \\
\text { série }\end{array}$ & $\begin{array}{l}\text { Vítimas: } 16,9 \% \text {. Agressores: } \\
\text { 29,4\%. }\end{array}$ \\
\hline 2001 & Wolke D, et al. ${ }^{21}$ & Inglaterra e Alemanha & $\begin{array}{l}2.377 \text { alunos ingleses e } \\
1.538 \text { alunos alemães de } \\
6 \text { a } 8 \text { anos }\end{array}$ & $\begin{array}{l}\text { Vítimas: } 54,7 \% \text { na Inglaterra e } \\
\text { 39\% na Alemanha. } \\
\text { Agressores: } 14 \% \text { e } 21,9 \% \text {, } \\
\text { respectivamente. }\end{array}$ \\
\hline 2003 & Dake JA, et al. ${ }^{2}$ & $\begin{array}{l}\text { Revisão de publicações } \\
\text { da Noruega, Suécia, } \\
\text { Dinamarca, Finlândia, } \\
\text { Alemanha, Espanha, } \\
\text { Itália, Inglaterra, } \\
\text { Escócia, Irlanda, } \\
\text { Austrália, Japão, Canadá } \\
\text { e EUA }\end{array}$ & $1^{\mathrm{a}}$ a $5^{\mathrm{a}}$ série & $\begin{array}{l}\text { Finlândia } 11,3 \% \\
\text { EUA } 19 \% \\
\text { Irlanda } 49,8 \%\end{array}$ \\
\hline 2004 & Fekkes M, et al. ${ }^{8}$ & $\begin{array}{l}\text { Holanda, novembro de } \\
1999\end{array}$ & $\begin{array}{l}2.766 \text { alunos do ensino } \\
\text { básico, de } 9 \text { a } 12 \text { anos }\end{array}$ & $\begin{array}{l}\text { Vítimas: 16,2\%. } \\
\text { Agressores: 5,5\%. }\end{array}$ \\
\hline 2008 & Cepeda-Cuervo E, et al. ${ }^{15}$ & $\begin{array}{l}\text { Ciudad Bolívar de } \\
\text { Bogotá, Colombia }\end{array}$ & $\begin{array}{l}3.226 \text { alunos, da } 6^{\mathrm{a}} \text { a } 11^{\mathrm{a}} \\
\text { série, com idades entre } \\
10 \text { e } 20 \text { anos }\end{array}$ & Vítimas: 21,8\%. \\
\hline 2008 & Due P, Holstein BE ${ }^{23}$ & $\begin{array}{l}66 \text { países - } 2 \text { estudos: } \\
\text { HBSC e GSHS, de } 2001 \\
\text { a } 2007 .\end{array}$ & $\begin{array}{l}218.104 \text { crianças entre } \\
13 \text { e } 15 \text { anos }\end{array}$ & Vítimas: 36,9\%. \\
\hline 2008 & Paredes, MT, et al. ${ }^{22}$ & $\begin{array}{l}\text { Cali, Colombia; outubro } \\
\text { de } 2005 \text { a abril de } 2006 .\end{array}$ & $\begin{array}{l}2.542 \text { alunos, da } 6^{\mathrm{a}} \text { a } 8^{\mathrm{a}} \\
\text { série, com idade média } \\
\text { de } 12 \text { a } 13 \text { anos }\end{array}$ & $\begin{array}{l}\text { Vítimas:24,3\%. Agressores: } \\
\text { 24,7\%. }\end{array}$ \\
\hline 2008 & Glew GM, et al. ${ }^{9}$ & $\begin{array}{l}\text { Costa oeste dos Estados } \\
\text { Unidos }\end{array}$ & $\begin{array}{l}5.391 \text { alunos do ensino } \\
\text { fundamental. }\end{array}$ & $\begin{array}{l}\text { Vítimas: } 15 \% . \\
\text { Agressores: } 7 \% . \\
\text { Ambos: } 4 \% .\end{array}$ \\
\hline 2011 & Pergolizzi F, et al. ${ }^{14}$ & $\begin{array}{l}\text { Naples, Flórida, Estados } \\
\text { Unidos, em } 2008\end{array}$ & $\begin{array}{l}346 \text { alunos de ensino } \\
\text { básico. }\end{array}$ & $\begin{array}{l}\text { Vítimas: 49,1\%. } \\
\text { Agressores: 43,6\%. }\end{array}$ \\
\hline
\end{tabular}

Tabela 2. Estudos brasileiros de prevalência de bullying

\begin{tabular}{|c|c|c|c|c|}
\hline ANO & AUTORES & LOCAL & POPULAÇÃO & PREVALÊNCIA GERAL \\
\hline 2005 & Lopes Neto $\mathrm{AA}^{5}$ & Rio de Janeiro, RJ & 5428 alunos de $5^{\mathrm{a}}$ a $8^{\mathrm{a}}$ séries & $\begin{array}{l}\text { Vítimas: } 16,9 \% . \\
\text { Agressores: } 12,7 \% . \\
\text { Ambos: } 10,9 \% .\end{array}$ \\
\hline 2009 & Francisco MV, et al. ${ }^{19}$ & Presidente Prudente, SP & $\begin{array}{l}283 \text { alunos da } 5^{\mathrm{a}} \text { e } 8^{\mathrm{a}} \text { série, } \\
\text { de } 2 \text { escolas: uma central e } \\
\text { outra na periferia }\end{array}$ & $\begin{array}{l}\text { Vítimas: } 14,9 \% \text { na } 5^{\mathrm{a}} \text { série, } \\
15,15 \% \text { na } 8^{\mathrm{a}} \text { série. }\end{array}$ \\
\hline 2010 & Malta DC, et al. ${ }^{18}$ & $\begin{array}{l}26 \text { capitais brasileiras e } \\
\text { Distrito Federal }\end{array}$ & 60.973 alunos da 8a série & Vítimas: 30,8\%. \\
\hline 2011 & Moura DR, et al. ${ }^{10}$ & Pelotas, RS & 1075 alunos da $1^{\mathrm{a}}$ a $8^{\mathrm{a}}$ séries & Vítimas: $17,6 \%$. \\
\hline
\end{tabular}

A prevalência encontrada de bullying nos diversos países e no Brasil atinge níveis alarmantes. O estudo do National Institute of Child Health and Human Development, nos Estados Unidos, com 15.686 alunos da $6^{\underline{a}}$ a $10^{\text {a }}$ séries evidenciou que $41,1 \%$ dos alunos enquadravam-se como vítimas ${ }^{20}$. $\mathrm{Na}$ Colômbia, o estudo com 3.226 alunos de $6^{\mathrm{a}}$ a $11^{\text {a }}$ séries, encontrou valor bastante semelhante, de $42,6 \%{ }^{15}$, bem como na Holanda, em que $44,6 \%$ de 2.766 alunos do ensino básico, relataram ter sido vítimas por pelo menos uma vez $z^{8}$. Nos dois estudos comandados pela Organização Mundial da Saúde, nos quais foram avaliadas 218.104 crianças, de 13 a 15 anos, em 66 países, em 2002, 32,1\% das crianças referiu ter sido vítima pelo menos uma vez nos últimos dois meses ${ }^{23}$. 
Nos últimos 10 anos, a prevalência de bullying nos Estados Unidos tem se mantido relativamente estável, ao redor de $40 \%$. Prevalência semelhante é observada em países europeus e latino-americanos, como Colômbia.

No Brasil, a prevalência de bullying encontrada é um pouco abaixo da vista na literatura: $27,8 \%$ de vítimas no estudo da ABRAPIA no Rio de Janeiro, RJ, com 5.500 alunos de $5^{\mathrm{a}}$ a $8^{\mathrm{a}}$ séries ${ }^{[5]}, 17,6 \%$ de 1.075 alunos de $1^{\underline{a}}$ a $8^{\underline{a}}$ séries em Pelotas, RS $^{10}$ e $29 \%$ de 283 alunos da $5^{\text {a }}$ a $8^{\text {a }}$ séries de Presidente Prudente, SP ${ }^{[19]}$. No estudo realizado pelo IBGE, o PeNSE - Pesquisa Nacional de Saúde do Escolar, em 2009, houve prevalência de bullying de $30,8 \%$, sem diferença entre as escolas públicas e privadas ${ }^{18}$. Apesar de um pouco menor que a prevalência nos outros países, esses dados não são menos estarrecedores e alarmantes. Quando comparados cronologicamente, tem-se um aumento da prevalência entre 2005 e 2011, com uma tendência em atingirmos os patamares observados na literatura estrangeira.

Em relação ao sexo do agressor, a maioria dos estudos demonstra que meninos estão mais envolvidos com o bullying físico e, as meninas, com bullying verbal ou indireto ${ }^{2,14}$. No geral, os meninos são mais prevalentes como agressores $8,10,14,18-21$, mesmo quando as vítimas são meninas ${ }^{19}$. Fato este observado tanto em estudos estrangeiros quanto brasileiros. Já em se tratando do sexo da vítima, os dados são um pouco divergentes. Alguns estudos apontam para a prevalência do sexo masculino ${ }^{20}$, enquanto outros afirmam não haver diferenças na prevalência em relação ao sexo ${ }^{8}$. Entretanto, o autor de clássicos estudos neste assunto, Olweus ${ }^{1}$ demonstrou que o menino é mais prevalente tanto como agressor quanto como vítima.

Quandocomparadasasidades dos envolvidos no bullying, tem-se que com o passar dos anos, e consequentemente das séries, a prevalência de bullying diminui ${ }^{2} 15,19$, fato este que é praticamente um consenso na literatura de revisão a cerca do assunto ${ }^{1-3}$. Nansel et al. ${ }^{20}$ demonstraram que a porcentagem de agressores diminui da $6^{\underline{a}}$ para a $10^{a}$ série, já a de vítimas diminui ainda mais. Em seu estudo, Francisco et al. ${ }^{19}$ caracterizaram que na $5^{\underline{a}}$ série era mais frequente a agressão física, já, na $8^{\underline{a}}$ série, eram as provocações verbais.

No tocante à distribuição de sexo e idade, não houve diferença entre os dados brasileiros e as séries estrangeiras.

Com relação às características de vítimas e agressores, pode-se subdivir os achados em aspectos físicos, psicológicos e comportamentais. No primeiro aspecto, de características físicas, têm- se achados um pouco discordantes na literatura: Olweus ${ }^{1}$, em seus estudos clássicos, não encontrou diferenças na aparência física entre as vítimas e seus pares. $O$ único ponto divergente encontrado era o tamanho, as vítimas tendiam a ser menores. Entretanto, outros estudos mostram que as vítimas muitas vezes apresentam uma marca que as distingue da maioria ${ }^{2,6}$, como obesidade, magreza excessiva, uso de óculos, etc.

Quanto às características psicológicas, a típica vítima é aquela com pouca habilidade de socialização, tímida, reservada e com baixa autoestima $^{6,20}$. Em geral, ela não dispõe dos recursos para reagir quando é submetida à agressão ${ }^{5}$. A solidão e baixa autoestima acabam sendo agravadas pelo bullying, sendo, assim, tanto fatores que tornam as crianças mais vulneráveis a essa prática como também seu agravamento é consequência dela ${ }^{2,24}$. Essas crianças são geralmente mais ansiosas, sensíveis e têm dificuldade de se expressar ${ }^{[6]}$, estampando suas inseguranças e tornando-se alvos fáceis. Fekkes et al. ${ }^{8}$ concluíram que as vítimas apresentam uma grande gama de sintomas psicossomáticos, entre eles, dores de cabeça, problemas relacionados ao sono, dor abdominal, ansiedade, falta de apetite, enurese, e ainda, maior prevalência de depressão.

Já o agressor tem em sua personalidade traços de desrespeito e agressividade. Também apresenta alto grau de ansiedade, bem como impulsividade. Demonstra falta de afeto pelo outro $2,5,6,20$.

Em se tratando das características comportamentais, os agressores costumam ter desempenho escolar regular ou ruim, são menos satisfeitos com a família e tem maior tendência a se envolver em comportamentos de risco, como uso de drogas e álcool, e condutas anti-sociais e ilegais ${ }^{2,5,20}$. Essas crianças muitas vezes têm histórico de abuso e violência doméstica, com pais pouco envolvidos no ambiente escolar ${ }^{2,3,5,6}$. Mais da metade dos agressores aos 20 anos já têm pelo menos uma condenação criminal ${ }^{4}$.

\section{CONCLUSÕES}

A prevalência do bullying no mundo e em nosso país é alarmante e alta. Não há diferenças significativas no perfil epidemiológico dos afetados quando se comparam os dados produzidos no o Brasil com os de outros países. As crianças que mais sofrem com esse problema são as de menor idade (ensino básico), de ambos os sexos (em alguns estudos há uma tendência maior em relação ao sexo masculino) e com personalidade 
introvertida e tímida. As consequências desta experiência têm um potencial devastador na vida jovem e adulta destes indivíduos. Tanto vítimas quanto agressores precisam ser identificados e amparados com políticas específicas e eficazes.

Deve-se ter em mente que os estudos aqui descritos, em sua maioria, utilizaram questionários preenchidos pelas próprias crianças, o que acarreta uma tendência a subestimar a frequência real, tanto de agressores quanto de vítimas.

Programas preventivos já mostraram sua efetividade. A ABRAPIA desenvolveu projeto em pouco mais de um ano com 5.500 escolares no Rio de Janeiro, RJ e obteve redução de $6,6 \%$ no número de vítimas e $12,3 \%$ de agressores ${ }^{5}$. Esse nível de melhora já deve ser comemorado, entretanto, pode ser ainda maior. A partir dos dados apresentados neste artigo, pode-se delinear uma população de risco para esse fenômeno e, assim, instituir medidas preventivas dirigidas a esse grupo específico, que resultariam mais frutíferas que medidas genéricas para crianças em geral.

Novos estudos são necessários para melhor elucidar os fatores causais que levam as crianças aos papéis de vítimas e de agressores, para que esses fatores sejam então saneados, evitando assim a delinquência futura dos envolvidos.

Fachin CG, Miziara CSMG. Epidemiologic profile of children involved in bullying. Saúde, Ética \& Justiça. 2012;17(1):30-7.

\begin{abstract}
Bullying is characterized by negative actions (physical, verbal or psychological aggressions) suffered by a student repeatedly over time, by one or more students, and there should be an imbalance of power between the aggressor and the victim. There are numerous consequences of this practice for both the victim and the offender, such as learning difficulties, poor school performance, decreased self-esteem, suicidal ideation and even suicide attempts. There is an increased incidence of bullying phenomenon in several countries in recent decades, including in our country. The aim of this study is to map the incidence of bullying reported in the literature, and outline an epidemiological profile of both the aggressor and the victim. The prevalence of bullying in different countries and in Brazil reaches alarming levels. Over the past 10 years, the prevalence of bullying in the United States have remained relatively stable, around $40 \%$. Similar prevalence is observed in European countries and in Latin American countries, like Colombia. In Brazil, the prevalence of bullying is a bit lower, however, there is an increase in prevalence between 2005 and 2011, with a tendency to reach the levels seen in foreign literature. Regarding the sex of the aggressor, most studies show that boys are more involved in physical bullying and girls, with verbal and indirect bullying. Regarding psychological characteristics, the typical victim is the one with little ability to socialize, shy, reserved and with low self-esteem. The abuser has in his personality traits of disrespect and aggression, and has a tendency to criminal offenses in adulthood. The consequences of bullying have the potential to devastate the lives of young and adult individuals. Both victims and perpetrators must be identified and supported with specific and effective policies.
\end{abstract}

KEYWORDS: Bullying/psychology; Child; Prevalence; Health profile; Chil psychology/education.

\title{
REFERÊNCIAS
}

1. Olweus D. Bullying at school: basic facts and effects of a school based intervention program. J Child Psychol Psychiatry. 1994;35(7):1171-90.

2. Dake JA, Price JH, Telljohann SK. The nature and extent of bullying at school. $J$ Sch Health. 2003;73(5):173-80.

3. Lyznicki JM, McCaffree MA, Robinowitz CB. Childhood bullying: implications for physicians. Am Fam Phys. 2004;70(9):1723-8.

4. Bostic JQ, Brunt CC. Cornered: an approach to school bullying and cyberbullying, and forensic implications. Child Adolesc Psychiatr Clin N Am. 2011;20(3):44765.
5. Lopes Neto AA. Bullying--aggressive behavior among students. J Pediatr (Rio J. 2005;81(5 Suppl):S16472.

6. Silva ABB. Bullying: mentes perigosas nas escolas. Rio de Janeiro: Ed Objetiva; 2009.

7. Barboza GE, et al. Individual characteristics and the multiple contexts of adolescent bullying: an ecological perspective. J Youth Adolesc. 2009;38(1):101-21.

8. Fekkes M, Pijpers FI, Verloove-Vanhorick SP. Bullying behavior and associations with psychosomatic complaints and depression in victims. J Pediatr. 2004;144(1):17-22.

9. Glew GM, et al. Bullying and school safety. J Pediatr. 
2008;152(1):123-8, $128 \mathrm{e} 1$.

10. de Moura DR, Cruz AC,. Quevedo AL. Prevalence and characteristics of school age bullying victims. J Pediatr (Rio J). 2011;87(1):19-23.

11. Kim YS, Leventhal B. Bullying and suicide. A review. Int J Adolesc Med Health. 2008;20(2):133-54.

12. Srabstein J. Deaths linked to bullying and hazing. Int J Adolesc Med Health. 2008;20(2):235-9.

13. Luukkonen $\mathrm{AH}$, et al. Bullying behaviour and criminality: a population-based follow-up study of adolescent psychiatric inpatients in Northern Finland. Forensic Sci Int. 2011;207(1-3):106-10.

14. Pergolizzi, F., et al., Bullying in middle school: results from a 2008 survey. Int J Adolesc Med Health. 2011;23(1):11-8.

15. Cepeda-Cuervo E, et al. Bullying amongst students attending state basic and middle schools. Rev Salud Publica (Bogota). 2008;10(4):517-28.

16. Center USSNTA. Safe school initiative: an interim report on the prevention of targeted violence in school. Washington, D.C.: US Depts of Treasury and Education with the support of the National Institute of Justice; 2000.

17. Anderson $M$, et al. School-associated violent deaths in the United States, 1994-1999. JAMA.
2001;286(21):2695-702.

18. Malta DC, et al. Bullying in Brazilian schools: results from the National School-based Health Survey (PeNSE), 2009. Cien Saude Coletiva. 2010;15(Suppl 2):3065-76.

19. Francisco MV, Libório RMC. Um estudo sobre Bullying entre escolares do ensino fundamental. Psicologia: Reflexão Crítica. 2009;22(2):200-7.

20. Nansel TR, et al. Bullying behaviors among US youth: prevalence and association with psychosocial adjustment. JAMA. 2001;285(16):2094-100.

21. Wolke $D$, et al. Bullying and victimization of primary school children in England and Germany: prevalence and school factors. Br J Psychol. 2001;92(Pt 4):67396.

22. Paredes MT, et al. Estudio exploratorio sobre el fenómeno del "Bullying" en le ciudad de Cali, Colombia. Rev Latinoam Cienc Soc Niñez Juv. 2008;6(1):295-317.

23. Due $P$, Holstein BE, Soc MS. Bullying victimization among 13 to 15-year-old school children: results from two comparative studies in 66 countries and regions. Int J Adolesc Med Health. 2008;20(2):209-21.

24. Neme $\mathrm{CMB}$, et al. Fenômeno Bullying: análise de pesquisas em Psicologia publicadas no período de 2000 a 2006. Pediatr Mod. 2008;44(5):200-4. 